\title{
KenSea - tsunami damage modelling for coastal areas of Kenya
}

\author{
John Tychsen, Ole Geertz-Hansen and Frands Schjøth
}

On 26 December 2004, the eastern part of the Indian Ocean was hit by a tremendous tsunami created by a submarine earthquake of magnitude 9.1 on the Richter scale off the west coast of Sumatra. The tsunami also reached the western part of the Indian Ocean, including the coastal areas of eastern Africa. Along the coast of Kenya (Figs 1,2) it resulted in a sudden increase in water level comparable to a high tide situation. This rather limited consequence was partly due to the great distance to the epicentre of the earthquake, and partly due to the low tide at the time of the impact. Hence the reefs that fringe two thirds of the coastline reduced the energy of the tsunami waves and protected the coastal areas.

During the spring of 2005, staff members from the Geological Survey of Denmark and Greenland (GEUS) carried out field work related to the project KenSea-development of a sensitivity atlas for coastal areas of Kenya (Tychsen 2006; Tychsen et al. 2006). Local fishermen and authorities often asked what would have been the effect if the tsunami had hit the coastal area during a high tide, and to answer the question GEUS and the Kenya Marine and Fisheries Research Institute (KMFRI) initiated a tsunami damage projection project. The aim was to provide an important tool for contingency planning by national and local authorities in the implementation of a national early warning strategy.

The tsunami damage projection project used the database of coastal resources - KenSeaBase - that was developed during the KenSea project. The topographical maps of Kenya at a scale of 1:50 000 have $20 \mathrm{~m}$ contour lines, which is insufficient for the tsunami run-up simulation modelling undertaken by the new tsunami project. Therefore new sets of aerial photographs were obtained, and new photogrammetric maps with contour lines with an equidistance of $1 \mathrm{~m}$ were drawn for a 6-8 km broad coastal zone.

The tsunami modelling is based on the assumption that the height of a future tsunami wave would be comparable with the one that reached the coastal area of Kenya in December 2004. Based on the regional geology of the Indian Ocean, it appears that the epicentre for a possible future earthquake that could lead to a new tsunami would most likely be situated in the eastern part of the ocean. Furthermore, based on a seismological assessment it has been estimated that the largest tsunami that can be expected to reach eastern Africa would have a 50\% larger amplitude than the 2004 tsunami.
It was therefore decided to carry out the simulation modelling with a tsunami wave similar to that of the 2004 event, but with the wave reaching the coast at the highest astronomical tide (scenario 1) and a worst case with a 50\% larger

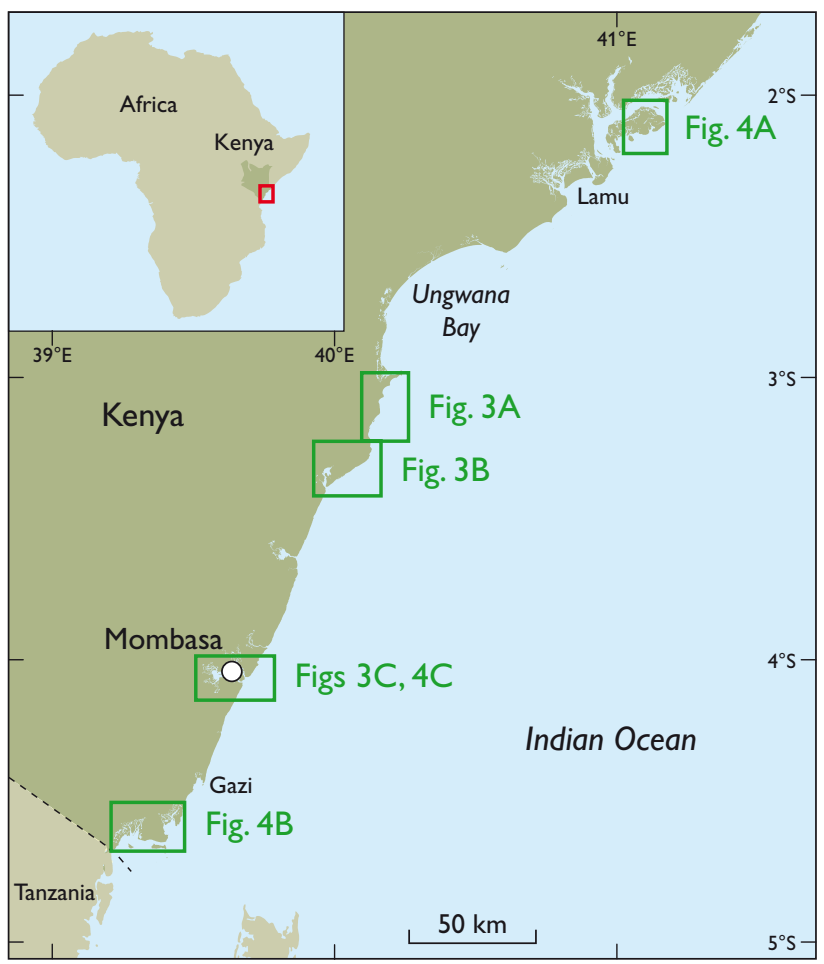

Fig. 1. Map of the coastal area of Kenya (red frame on index map). The green frames show the locations of the maps shown in Figs 3-4.

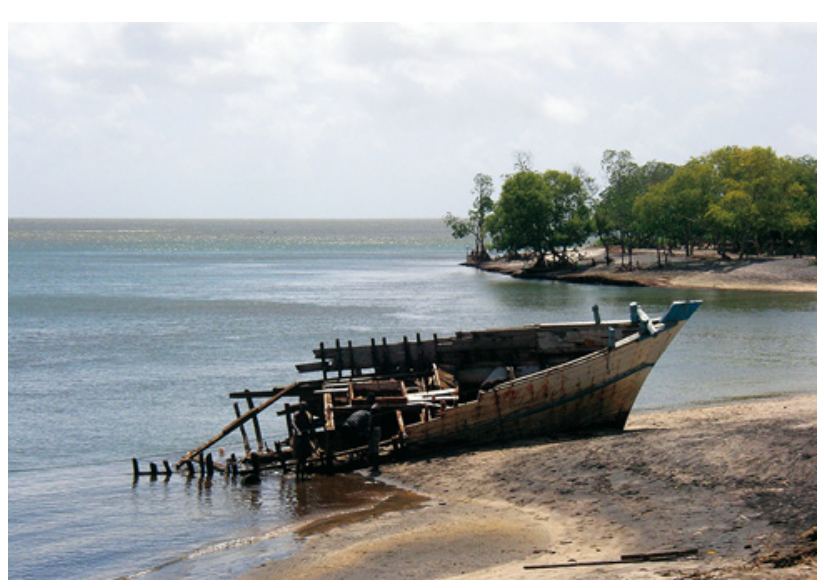

Fig. 2. A fishing vessel lying on the beach east of Ngomeni. The vessel was wrecked by the tsunami in December 2004 (see Fig. 3A for location). 

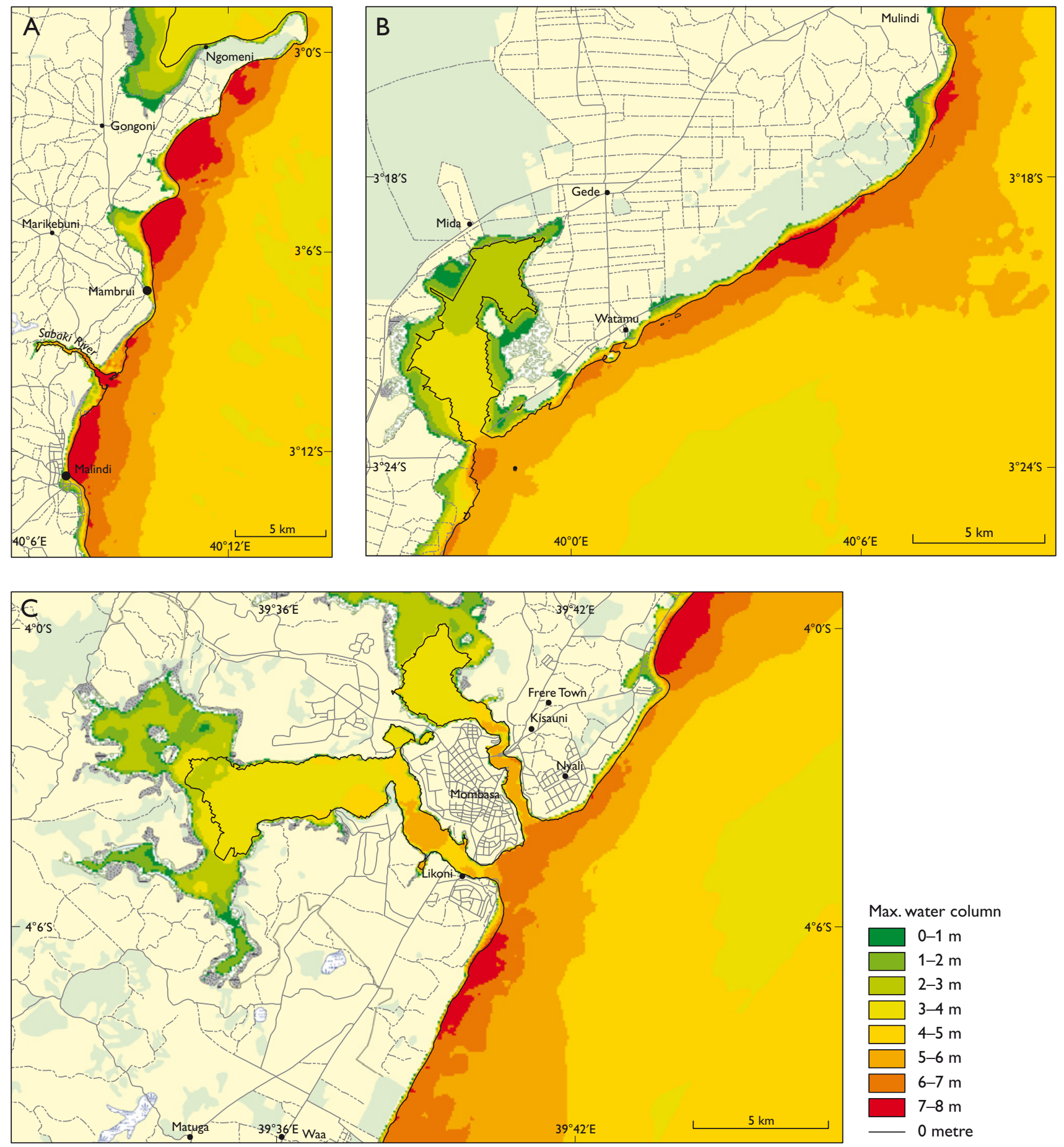

Fig. 3. Scenario 2, showing maximum simulated water levels north of Sabaki River, in the Watamu-Malindi area, and around Mombasa for a tsunami reaching the coast at high tide, and with a 50\% larger amplitude than the 2004 tsunami. At sea, sea surface elevation is shown relative to mean sea level, whereas on land the water level is relative to the land surface and therefore shows flooding heights (see Fig. 1 for location).

amplitude (scenario 2: Fig. 3). The 2004 tsunami documented that the coastal belt of mangrove swamps provided some protection to the coastline by reducing the energy of the tsunami. Hence we included in this study a scenario 3 (Fig. 4), in which the mangrove areas along the coastline were removed. Maps for the three scenarios have been produced and show the areas that would be flooded, the degree of flooding, and the distribution of buildings such as schools and hospitals in the flooded areas. In addition, the force and velocity of the wave were calculated (COWI 2006). 

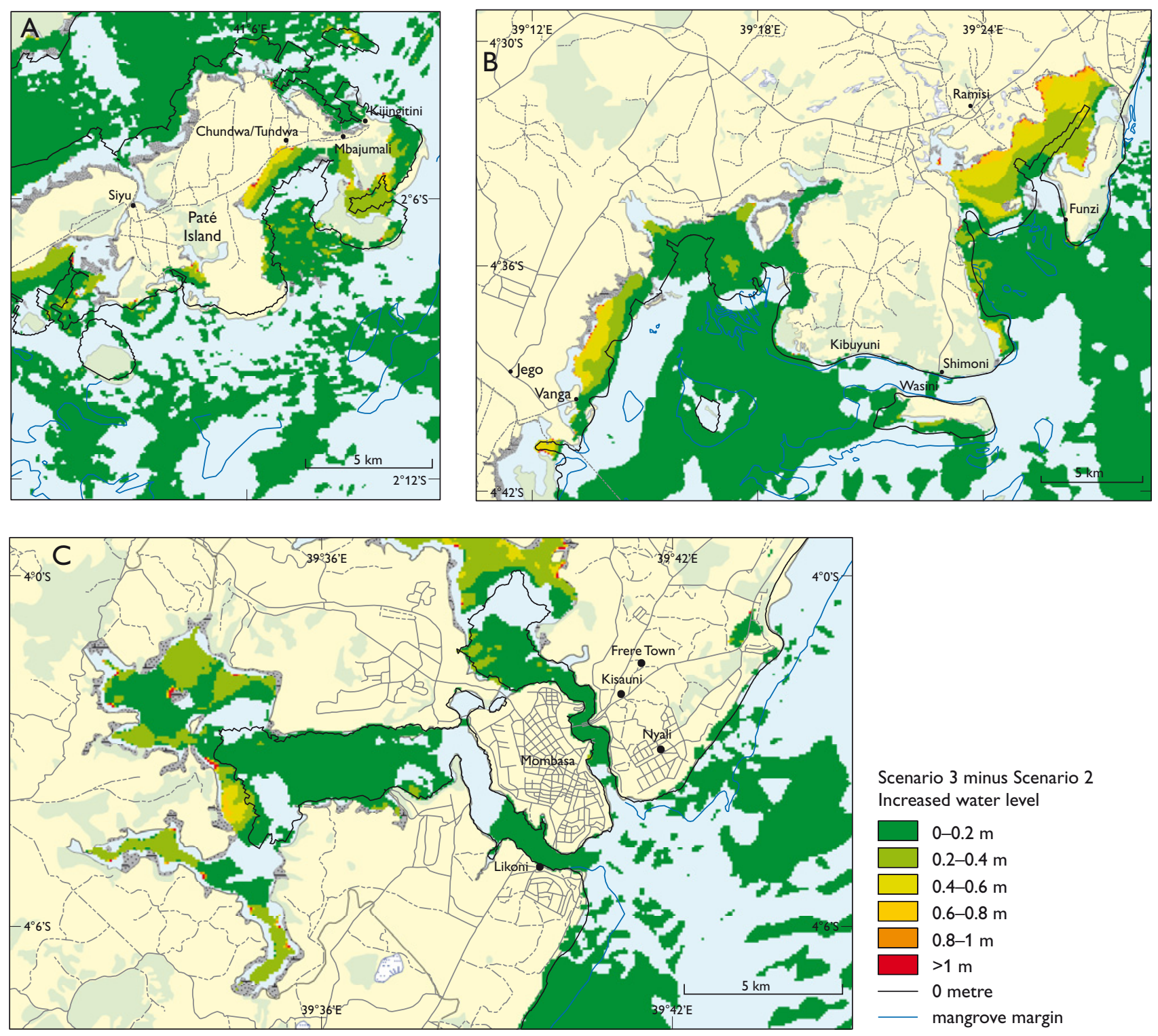

Scenario 3 minus Scenario 2 Increased water level

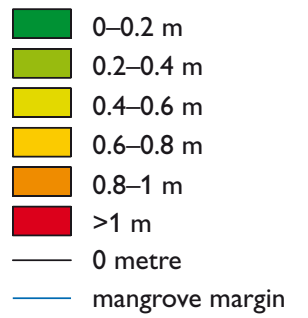

Fig. 4. The effect of mangroves. The figure shows the difference between scenario 3 (all mangrove removed) and scenario 2 (mangrove present) for three important mangrove areas (Paté Island, the Vanga-Shimoni-Funzi area and the Mombasa area). The green 0-0.2 m signature in open water can mostly be regarded as noise from the model. The only marked difference between the models is seen behind areas with dense mangroves (see Fig. 1 for location).

\section{The run-up simulation model}

The study used the MIKE $21 \mathrm{BW}$ model, which is a 2-D hydrodynamic model from the MIKE modelling suite developed by the Danish Hydraulic Institute. The modelling was undertaken by COWI A/S in Denmark (COWI 2006). The model setup included detailed bathymetry and topography of the area and data on the surface properties (e.g. sand, reef, rock, mangrove, forest, town), which provide information on bed resistance. The model covers an area of $49000 \mathrm{~km}^{2}$ with a grid size of $100 \times 100 \mathrm{~m}$. Thus the total number of grid cells is 4900000 . The topographical data mainly derive from the detailed topographic maps that were drawn from the new aerial photographs. Where necessary these data were comple- mented with data extracted from existing topographic maps. The topographical data thus only cover elevations above mean sea level. Bathymetrical data were extracted from CMap, a world wide digital navigational chart, by a module that produces bathymetrical data that can be used directly by the MIKE models. The C-Map data include water depths at and below the chart datum. The topography between mean sea level and chart datum was interpolated.

No measured boundary data were available, and a normal calibration of the model was therefore not possible. Only one single high-resolution time series of water level changes during the 2004 tsunami incident is available, from the port of Lamu in the north. The offshore boundary conditions off 
Lamu were back-calculated by a trial and error approach until the model reproduced the recorded time series at Lamu. By this approach, bed resistances could not be used for calibration, but were set to well-established values for the various types of sea bed and land surfaces mapped and described by Tychsen (2006). The resulting boundary conditions (i.e. the offshore tsunami wave train) were then applied to the full length of the Kenyan coast.

\section{Model results}

A few examples of the model results are illustrated here, and more details can be found in the project reports (COWI 2006; GEUS 2007). All data and results are stored in electronic form in the KenSea database located at KMFRI in Kenya. Three areas have been selected to give an impression of the effects of a possible new tsunami. The risk of a scenario 2 incident is extremely small, but the model helps to pinpoint the most sensitive areas along the coast (Fig. 3).

\section{Effects of mangrove}

The mitigating effects of mangrove forests on the destructive powers of tsunamis have been described and discussed by several authors following the December 2004 tsunami (e.g. Kathiresan \& Rejendran 2005). Scenario 2 was therefore remodelled with all mangroves removed, i.e. with bed resistance corresponding to normal sea bed (scenario 3).

The difference between models with and without mangrove is not obvious, and it was therefore decided to subtract scenario 2 from scenario 3 to isolate the mangrove effects. This method creates some noise and artefacts, but the conclusion is that the effect on water level is small, less than 20 $\mathrm{cm}$ in most places; however, behind wide and somewhat exposed mangroves the difference can be up to 60 or $70 \mathrm{~cm}$. In addition, the flooding extends up to $300 \mathrm{~m}$ farther inland when the mangrove is removed. The most significant effect is found behind the mangrove areas north of Vanga, behind Funzi, near Gazi, in the south-western part of Ungwana Bay, and on Paté Island (Fig. 4).

The effects in Kenya of removing the mangrove are smaller than expected from other studies (Gelfenbaum et al. 2007). This is not because the mangroves do not mitigate tsunami waves, but because mangroves along the coast of Kenya are mostly found in areas already protected from direct wave exposure, as found in sheltered bays and lagoons, and behind islands or wide reefs. Mangroves do not usually grow naturally along the most exposed coastlines characterised by erosion. This is partly due to the exposure, but mainly due to the lack of suitable substrates for the roots.

\section{Recommendations}

An important output of the project was the following set of recommendations to the Government of Kenya:

- It is recommended that an Indian Ocean tsunami warning system is developed, similar to the well-developed system in the Pacific Ocean.

- A post-2004 tsunami study showed a marked lack of knowledge of tsunamis among the coastal communities. Hence there is a need to create public awareness of the causes and potential impacts of tsunamis to enable the local population to take appropriate action when an alarm is raised and thus to minimise the effects of future tsunamis.

- Mangrove forests play an important role in mitigating the impact of tsunami waves. It is recommended that the Department of Forestry in conjunction with local communities rehabilitate areas where mangrove has been cut down.

- In high-risk areas, the provincial administration in collaboration with the Disaster and Tsunami Management Committee should educate the population living in those areas. This would help them to cope better with a tsunami disaster, both physically and psychologically.

\section{References}

COWI 2006: Tsunami run-up simulation model for the near shore part of the coastal area of Kenya, 49 pp. Unpublished report, COWI for the Geological Survey of Denmark and Greenland, Copenhagen.

Gelfenbaum, G., Vatvani, D., Jaffe, B. \& Dekker, F. 2007: Tsunami inundation and sediment transport in vicinity of coastal mangrove forest. In: Kraus, N.C. \& Rosati, J.D. (eds): Coastal sediments '07. Proceedings of the Sixth International Symposium on Coastal Engineering and Science of Coastal Sediment Processes, 1117-1128. 13-17 May 2007, New Orleans, Louisiana.

GEUS 2007: The KenSea II project. Tsunami damage projection for the coastal area of Kenya, 70 pp. Unpublished report, Geological Survey of Denmark and Greenland, Copenhagen.

Kathiresan, K. \& Rejendran, N. 2005: Coastal mangrove forests mitigated tsunami. Estuarine, coastal and shelf processes 65, 601-606.

Tychsen, J. 2006 (ed.): KenSea - environmental sensitivity atlas for coastal area of Kenya, 76 pp. Copenhagen: Geological Survey of Denmark and Greenland

Tychsen, J., Geertz-Hansen, O. \& Kofoed, J. 2006: KenSea - development of an environmental sensitivity atlas for coastal areas of Kenya. Geological Survey of Denmark and Greenland Bulletin 10, 65-68. 